\title{
ARTICULACIÓN DE UNA POÉTICA PARA LA CIUDAD ENMUDECIDA EN LAS CRÓNICAS DE JOSÉ DONOSO*
}

\author{
Andrés Ferrada Aguilar \\ Universidad de Chile \\ ferrada2010@gmail.com
}

\section{RESUMEN / ABSTRACT}

El artículo se centra en una selección de crónicas en las que José Donoso se aproxima a la ciudad de Santiago en la década del ochenta, desnaturalizando los referentes urbanos. Mediante una poética que pone énfasis en el carácter transformador del artificio, el autor narra una ciudad confrontada a la mudez de sus barrios y prácticas urbanas. Se articula así, en el plano de la escritura, una voz para la ciudad que desajusta la homogeneidad que tanto el género cronístico como la oligarquía contemporánea imponen en la representación de la urbe.

Palabras clave: escritura referencial, crónica urbana, ciudad de Santiago, poética, voz.

The article focuses on a selection of chronicles in which José Donoso provides a denaturalized image of the city of Santiago in the 1980s. By stressing a poetics of transformation, the author narrates a city that confronts the silence pervading its urban practices and neighbourhoods. Under this guise, Donoso's writing tactically articulates a voice for the city that challenges both the homogeneity imposed by traditional renditions and the order of a contemporary oligarchy.

KEY WORDS: referential writing, urban chronicles, city of Santiago, poetics, voice.

Este artículo refleja algunas ideas de mi tesis doctoral "La ciudad y su espacio literario en las crónicas de José Donoso" (Universidad de Chile, 2013) dirigida por Leonidas Morales, a quien agradezco su valiosa orientación. 


\section{INTRODUCCIÓN}

La enunciación de Santiago en las crónicas de José Donoso revela circunstancias de orden público y biográfico que tensionan progresivamente la relación del autor con su ciudad natal. Entre otras, destacan su retorno definitivo a Chile después de casi dos décadas de residencia en el extranjero, la dictadura pinochetista y, bajo esta condición, el conflicto que suscita la politización de la escritura a inicios de los ochenta (Donoso, Diarios 340). Desde estas fisuras las crónicas del autor promueven una modulación inédita de la ciudad que instala un espacio literario por medio de una poética de artificio. El mismo autor sostiene en variedad de tonos que la literatura es, ante todo, creación con la palabra, estilización, concreción de una estética (Donoso, Artículos 210). En este sentido, el referente urbano se descompone con recursos literarios que privilegian un registro acústico, encarnado en el protagonismo de la voz por sobre el dominio especular como modo sensible de aprehender la ciudad. La homogeneidad de las prácticas urbanas -reflejada en la imagen recurrente del inventario- se contrapone a la posibilidad de crear una voz que subvierte la uniformidad del paisaje santiaguino. Esta aspiración literaria se advierte en "El retorno del nativo" (1981), "Idioma y retorno" (1983), "Voz e inventario" (1983) y "El espacio literario" (1986), trabajos que remiten a la articulación de una poética para la representación de la ciudad.

El interés estético que la ciudad despierta en Donoso, como asimismo el reconocimiento de su poeticidad, no emerge abruptamente. Por el contrario, expresa una larga y estrecha relación del autor con espacios y subjetividades signados por la degradación. Tematizado tanto en sus crónicas como en las novelas, este deterioro acusa la impotencia de configurar un orden, o un idioma, que permita autentificar la identidad. Al vincular a Donoso con la novela del escepticismo, José Promis percibe en este programa narrativo "procesos de agonía irrecuperables" (930) que involucran a los miembros de la alta burguesía santiaguina, es decir, a sujetos con una vocación decididamente urbana. La obra de José Donoso alcanza notoriedad en 1957 con la publicación de Coronación, que Editorial Nascimento elogiara en su portada como una narración "que reúne tantas cualidades que pasará a ocupar un lugar en la primera fila de nuestra novelística urbana". Los cuentos "Paseo", "Una señora" y "China" también revelan una disposición a complejizar las escenas citadinas, ofreciendo una cartografía de los espacios públicos a través de recorridos azarosos e impremeditados. 
Estos trabajos instalan una crisis que irá consolidando un registro valioso de la ciudad y el sujeto urbano en la obra de José Donoso. En 1960, Revista Ercilla publica "Viaje a lomo de libro", artículo en el que el escritor se propone "viajar por el país llevado por sus libros, para escuchar los ecos literarios que algunos lugares despiertan en mí" (Escribidor 217). Al concluir leemos una acotación de sumo interés: "Además de adolecer de un centralismo económico, Chile sufre un centralismo literario muy comprensible. Los escritores santiaguinos son innumerables. Sin embargo, no existe un escritor de la ciudad, en el sentido que lo es Edwards Bello, de Valparaíso, o Eduardo Mallea de Buenos Aires" (220). En este itinerario, Santiago evoca la esterilidad de su literatura urbana. La imagen en ciernes de una ciudad silente y de un idioma capaz de amplificar sus espacios son ejes temáticos que Donoso abordará nuevamente en la década del ochenta.

En este contexto, las crónicas del autor esbozan zonas críticas para la enunciación de una literatura con ecos santiaguinos. De acuerdo a Donoso, esta literatura debería gestarse al amparo de "espacios estéticos cargados de emoción" (Artículos 206) en cuyo centro el lenguaje poético transgrede creativamente las imposiciones del poder. La trayectoria de esta crítica no reduce el acto de creación verbal, cuya autonomía el autor considera esencial, a una politización de la palabra. Será un desplazamiento que se sostiene sobre un pacto en que el escritor y el lenguaje reconocen la capacidad creativa del artificio. En la lectura que este artículo propone, las crónicas de José Donoso propician un espacio-tiempo insospechado en el decurso de una poética que desnaturaliza la homogeneización de la ciudad, dejando al descubierto "tradiciones encarnadas en lugares ahora usurpados o destruidos o anulados" (206). Al transgredir los aspectos prototípicos del género crónica-como la recomendación a narrar con agilidad las contingencias urbanas- los trabajos de Donoso desajustan el referente ciudad en clave literaria, y movilizan al mismo tiempo una crítica del poder. Estos aspectos quedan de manifiesto en una serie de ensayos que reflexionan sobre la "violación de la palabra, que tiene viejo arraigo entre nosotros"1 (Diarios 338). La convergencia de ocupaciones literarias y críticas, esta vez en la narrativa de Donoso, evidencia un interés

Sobre este aspecto, destacamos las apreciaciones del autor en "La libertad y el lirismo" (1988), en Artículos de incierta necesidad. Otros trabajos relacionados son "Efemérides" (1984), "La homogeneidad nacional" (1985), "País 'desinflado"” (1987) y "La palabra traicionada” (1988), en José Donoso. Diarios, ensayos, crónicas. 
creciente por "la desintegración progresiva del sujeto como una estructura unitaria" (Morales, Novela chilena 44). Esta fragmentación conforma una obsesión temática vinculada al despliegue de una ideología del poder que, al interior de las crónicas, adquiere una marcada orientación crítica.

En el ámbito de la modernidad latinoamericana, la crónica ha suscitado multiplicidad de enfoques en torno a un género cuya versatilidad señala, a fin de cuentas, su constante ensamblaje discursivo. A mediados del siglo XX, la tercera mundialización europea y sus "rupturas históricas cualitativas" (Mongin 176) harán insostenible el divorcio entre la evolución del género y la trayectoria de la modernidad en nuestro continente. El surgimiento de la crónica coincide con un fenómeno de mayor envergadura, la modernización literaria y cultural de América Latina que Ángel Rama sitúa entre 1870 y $1910^{2}$. En este sentido se observa una notable sincronía entre la instalación de un objeto textual inédito y los efectos tempranos de una modernidad importada en la región. El género de la crónica reveló, además, las aspiraciones de una literatura modernista que vendría a consolidar una poética propia. No está de más recordar que los trabajos de José Martí y Rubén Darío, por ejemplo, oponen a las convenciones discursivas de la prensa periódica una inflexión escritural que cristaliza una ética y una estética de experimentación. Darío entendió muy bien que la crónica constituye, efectivamente, "el laboratorio de ensayo del estilo" (Cit. en Rotker 96).

A principios del siglo XX la amalgama de una técnica literaria con las exigencias de la prosa periodística se desajusta, originando objetos textuales distintivos. Surge, en palabras de Rotker, una insospechada "relación entre los enunciados, las formas literarias, y los campos semióticos presupuestos por la autoridad literaria, diferenciada de la autoridad política" (93). Sin perder del todo sus vínculos de complicidad, tanto la poesía como la crónica adoptan un sello discursivo particular. Este hito modernista, en conjunto

2 Para Rama, la modernización "no es una estética, ni una escuela, ni siquiera una pluralidad de talentos individuales como se tendió a ver en la época, sino un movimiento intelectual, capaz de abarcar tendencias, corrientes estéticas, doctrinas y aun generaciones sucesivas que modifican los presupuestos de que arrancan". El autor identifica esta época con una modernización literaria y la necesidad de generar "un discurso crítico que abarque todos los países que se designan con el rótulo América Latina y que procure reconocer la multiplicidad de líneas de desarrollo de cualquier tiempo histórico con una concepción nítidamente culturalista". En La crítica de la cultura en América Latina, 1985, pp. 89-90. Énfasis del autor. 
con una producción cronística que en Chile alcanza un nivel sobresaliente en la escritura de Joaquín Edwards Bello, constituye un campo preliminar desde el cual es posible leer los trabajos de José Donoso. Sin embargo, y en concordancia con el propósito de este estudio, estos antecedentes nos interesan principalmente para establecer cómo las crónicas de Donoso ponen en crisis la construcción discursiva del género a partir de la enunciación de la mudez de Santiago de Chile en la década de 1980.

\section{CLAVES DE UNA POÉTICA URBANA EN “VOZ E INVENTARIO”Y "EL ESPACIO LITERARIO"}

"Voz e inventario" (1983) desarrolla temas indispensables en la cronística del autor: la mudez literaria y cultural de Santiago, su enunciación a contraluz de otras urbes latinoamericanas y la posibilidad de gesticular un espaciotiempo cotidiano para el despliegue de su música. A partir de la revisión de un estudio titulado Inventario de una arquitectura anónima (1982), Donoso concluye que en los barrios de Recoleta e Independencia las construcciones tradicionales perviven en el anonimato porque no lograron exteriorizar, ya sea bajo la forma de un idioma o una música, "una conciencia de sí" (Artículos 159). Entra en escena, de acuerdo al autor, la imagen de una ciudad que a pesar de sus innegables méritos estéticos y urbanos parece sin alma, desprovista de un registro literario. A pesar de las bellas fotografías que acompañan el Inventario, éste "permanece estático, mudo, científico. No vibra aún con las resonancias de nuestra música y de nuestra poesía que conmueven sus piedras" (162).

En estas reflexiones el autor destaca, como hiciera en "Viaje a lomo de libro", la ausencia de un escritor capaz de construir una cadencia literaria para Santiago. La forma en que Donoso entiende la poesía de una ciudad se percibe más claramente cuando reflexiona que

la gran literatura argentina -fuera de la literatura rural y gauchescaes una literatura urbana, y constantemente ha ido construyendo dos cosas importantes: uno, el mito poético de la ciudad de Buenos Aires, la fantasía de sus barrios y arrabales, de su centro y sus virtudes y sus vicios y sus personajes, y la interacción de sus clases sociales; y dos, un idioma referido a actitudes populares, popular que puede ser de cualquier clase social pero es de todos reconocible, asumido como idioma de la literatura (Artículos 156-157). 
Concebida como realidad autentificada por un acto de creación, la escritura de Donoso entra en crisis en un horizonte definido "por el fenómeno de [...] la globalización de la 'mercancía' (convertida en protagonista estelar), y que, en términos menos genéricos, se traduce en la globalización simultánea de la sociedad de mercado y de la cultura que sostiene y la sostiene: la cultura del consumo" (Morales, Aisthesis 222).

Se suman a este escenario dos aspectos interrelacionados: la dictadura militar y la censura. Dentro de esta condición, el diálogo entre poesía, ciudad y sujeto enunciante promueve un espacio-tiempo ${ }^{3}$ que desajusta la reificación impuesta por formas museificadas de habitar la ciudad. Siguiendo las ideas del autor en "El espacio literario" (1986), las ciudades poseen una vocación que consiste en generar idiomas capaces de relatar la historicidad y corporalidad de sus espacios, con mayor razón si éstos han sido silenciados. Después de felicitar la obra de escritores europeos y americanos que han "construido ciudades inolvidables con palabras que son más emocionantes que las ciudades de piedra, historia y barro de la realidad, y a veces más eternas", Donoso concluye: "la ciudad imaginada vive y duele e invade el texto con su pasión e inexactitudes y limitaciones, como en el caso de Buenos Aires de Borges, por ejemplo, no descrito, pero sí, emocionalmente presente, determinando toda una parte de la literatura borgeana" (Artículos 116). El espacio literario, además, insufla "el verdadero corazón de la novela que hace pulsar su sangre, haciéndola volver [a este sitio] para adquirir más y más fuerza, y alimentar más personajes y situaciones y significaciones" (115). La imagen de un contacto sanguíneo entre escritura y ciudad es significativa, por cuanto admite un espacio de alteridad que se sobrepone a las estrategias de homogeneización de las prácticas urbanas ${ }^{4}$.

\footnotetext{
Ante el dilema de un sujeto imposibilitado de resolverse en la "exterioridad de una ciudadanía", pero dispuesto al mismo tiempo a generar "procesos de subjetivización", Gilles Deleuze plantea "suscitar acontecimientos, aunque sean mínimos, que escapen al control, hacer nacer nuevos espaciotiempos [sic], aunque su superficie o volumen sean reducidos [...]. La capacidad de resistencia o, al contrario, la sumisión a un control, se deciden en el curso de cada tentativa". En Conversaciones, 1990, p. 149.

Este estudio aborda la imagen no solo como parte del lenguaje figurativo en la retórica tradicional, sino también como construcción sensible que reconoce la presencia visual y acústica de la ciudad. Partícipe de una modificación innovadora del espacio urbano, la imagen revela un dinamismo creativo y a un sujeto que se "constituye por la acción poética", ofreciendo así una fluidez contrapuesta a la estratificación de las representaciones. Sobre este aspecto, ver La presencia y la ausencia, de Henri Lefebvre, 2006, p. 246.
} 
Cada vez que Donoso se refiera a la literatura lo hará guiado por este sentido de elaboración de la referencialidad. "El novelista forja otro mundo con datos del mundo 'real', que aluda o contiene esencialmente una deformación de ese mundo 'real', y esa deformación es el quehacer artístico" (Godoy 26), estima el autor en una entrevista de 1971. Esta reformulación de la fisonomía de la realidad, a diferencia de la estética dickensiana que deviene caricaturización grotesca $^{5}$, sugiere una interpretación nueva de la experiencia acentuando su heterogeneidad y posibilidades de expresión. Una década más tarde en "El retorno del nativo", el escritor afirma:

Quisiera comprender y transmitir, después de tan larga ausencia, lo que es esta ciudad, que es la mía, y mi ambivalente relación con ella, con su presente y pasado, y poder manejarla de modo de lograr transformarla en un espacio estético que contenga un nivel de crónica, pero que no se reduzca a ella, porque debe ser terreno fértil, sobre todo, para esa "fantasía" de la que los chilenos tanto desconfiamos (Artículos 210-211).

La ciudad estimula fantasías para una escritura que desnaturaliza las narraciones vertidas en "papel de fumar", centrando su atención en los hitos interrumpidos o degradados del paisaje urbano. La habilitación de estas expresiones no pasa necesariamente por su embellecimiento o estilización, sino por su visibilidad en un trabajo crítico que transparenta la homogeneización cívica, estética y arquitectónica de Santiago.

Conviene reiterar que si bien "Voz e inventario" y "El espacio literario" se publican en los ochenta, el interés por la ciudad en la escritura de Donoso ya delata una presencia relevante en la década del sesenta. En un número

5 Donoso estima que los personajes en Los miserables de Víctor Hugo y Bleak House de Charles Dickens no poseen hondura psicológica en el sentido contemporáneo: "se repiten a sí mismos en vez de desarrollarse, carecen de contradicciones y facetas. Son sus seres monstruosos, sus Mmes. Thenardier, sus abogados venales y comerciantes sin corazón, los que son verdaderas creaciones, no aquellos personajes que deberían tener tamaño natural: los esperpentos hacen vivir estas novelas". En "Las pecadoras", Artículos de incierta necesidad, 1998 , p. 242.

6 En el artículo "No existe homogeneidad de la raza", Joaquín Edwards Bello sostiene que el periodista escribe "como en papel de fumar". Agrega que el "verdadero periodista no tiene tiempo para la poda y la meditación, y aunque sepa ensartar gemas auténticas en el hilo de sus impresiones, su obra, para el intelectual profesional tiene todo de bagatela". En Crónicas, 1964, p. 111. 
importante de crónicas de este período el autor registra sujetos y prácticas urbanas en escenas que se debaten entre tradición y modernidad ${ }^{7}$. Su narrativa no queda exenta de estas cuestiones. La ciudad evocada en El lugar sin límites (1965) exacerba irrealizables promesas de transformación, tanto para el pueblo como para los personajes. Por su parte, el desarrollo del conflicto en Este domingo (1966) supone relaciones entre espacios socialmente incompatibles, como el barrio burgués y los márgenes anómicos. Ahora bien, al igual que la "constante diversificación y expansión regulada" (Morales, Donoso, 70 años 40) que experimentan los temas en su prosa de ficción, las crónicas movilizan ideas recurrentes que configuran un territorio discursivo principalmente a partir del oficio del novelista.

En efecto, en "El retorno del nativo", Donoso apela a un modo de aproximación a la ciudad cuando se propone "poner en actividad las prerrogativas del novelista: observar, escuchar, preguntar, para permitir que Santiago me vaya invadiendo" (Artículos 204). Una poética, bajo este enfoque, trasforma la disponibilidad sensible de la ciudad en una experiencia estética y literaria en estrecho vínculo con los hitos de la biografía personal. "Uno piensa", destaca el escritor, "en La ciudad, en Ithaca de Kavafis, y lo inexorable que es el haber nacido y pertenecido a una ciudad, y cómo se hace necesario volver a ella" (Artículos 117). De aquí también la identificación del autor con la novela El año de la muerte de Ricardo Reis (1984), de José de Saramago, cuyo protagonista "regresa a su Lisboa natal a morir, después de casi veinte años en Brasil. Relata la pequeña vida diaria de un hombre solo y un poco perdido, pero de gran inteligencia, al reencontrar esta ciudad que es la suya" (117). A pesar de las diferencias que marcan las circunstancias de enunciación de estos sujetos, el hablante del poema de Kavafis, el personaje de Saramago y José Donoso comparten la encrucijada que significa el trance del retorno a la ciudad natal. Además de las simetrías entre los temas y la biografía de Donoso, estas citas revelan las claves de una poética que se fundamenta parcialmente en un vínculo irrenunciable entre la historia de la ciudad y el "nativo" que la habita. La disponibilidad de estas claves, sin embargo, no se reduce solo a las alusiones literarias, sino que se enriquece con comentarios sobre los lenguajes del paisajismo, la arquitectura, la pintura, la música y la fotografía. 
En este sentido, la admiración de Donoso por el trabajo de Julia Margaret Cameron en "Dos lentes" (1979) es decidora. Para ella, "ya en 1870, y siendo una de las primeras fotógrafas que así la entienden, la fotografía es un arte. Ella misma dice que "las tomó con un foco un poco suave para que la fotografía se separe de la realidad" (Artículos 456-457). A partir de esta nota, el autor estima que lo relevante es "la conciencia estética de que todo arte es, en parte artificio: realizar esto, incorporar esta conciencia a la técnica y al contenido del arte, es crear una poética"8 (457). Esta poética implica un acto deliberado que discrimina y luego desnaturaliza la presencia sensible de los objetos, transformándolos en material literario. "Dos lentes" presenta las poéticas en los trabajos de dos reconocidas fotógrafas, los cuales entregan pistas adicionales para comprender la "conciencia estética" con la que Donoso enuncia la ciudad en sus crónicas.

Por un lado, Diane Arbus "sobrepasa el simple feísmo y tremendismo gótico a que tanto se presta Nueva York" bajo una poética que "muestra desnudando, física y moralmente a los que prestaron sus personas a su humanísimo lente". Julia Cameron, en tanto, "acepta la imagen que sus personajes quieren dar de sí mismos" (457). Si bien ambas artistas tensionan estéticamente la realidad, esta reformulación resulta de procedimientos singulares que podemos relacionar con el discurso cronístico y el literario, respectivamente. Mientras el primero se debate en condiciones de existencia cotidiana-Arbus intentará "hacer crónica de la soledad neoyorquina" (452)-, el segundo desajusta la familiaridad de las rutinas periódicas instalando modos alternos de narrar el complejo dinamismo de la ciudad.

Las indicaciones de José Donoso sugieren que en sus trabajos referenciales la ciudad pasa por el cedazo de la crónica y la novela. La imagen de Santiago obedece a estos dos lentes, cada uno con sus enfoques específicos, pero complementarios a la vez. "Lo nuestro", "Idioma y retorno", "Nostalgia del café" y "Voz e inventario" son crónicas que lamentan el empobrecimiento cívico y cultural de los espacios públicos y entregan, asimismo, una versión inédita de estos lugares. Más adelante se discutirán los recursos metafóricos

\footnotetext{
En un fragmento de diario fechado el 3 de febrero de 1982, Donoso retoma brevemente este asunto: “¿Por qué nuestra pasión -y mi gran pasión, muy en particular-por los retratos de estudio del siglo pasado? ¿Por Nadar y Julia Margaret Cameron y Lewis Carroll y todos los demás, que fuerzan a sus sitters a tomar poses falsas, de donde, sin embargo, sale algo que es verdadero, porque es otra forma de fantasía?". En José Donoso. Diarios, ensayos, crónicas, 2009, p. 499.
} 
que intervienen en la percepción del silencio santiaguino desde un imaginario de la decadencia ya bien asentado en la narrativa donosiana. La sintaxis, por su parte, refleja la fragmentación del espacio y las dificultades con las que el nativo enfrenta esta experiencia. En los viejos barrios del poniente, por ejemplo, apreciamos cómo "los cités y las pensiones y las esquinas y las iglesias, parecen, justamente anónimas porque no generaron una conciencia de sí, ni un idioma, ni una música ni una poesía" (Artículos 159). En este caso, la conjunción no solo organiza impresiones relativamente objetivas del paisaje urbano, elabora además minuciosos catálogos que crean la ilusión de conjunto mientras un ojo y un oído aún escépticos recorren "una ciudad sin alma, sin voz" (159).

Hemos señalado que la fascinación por los hitos urbanos degradados motiva la traducción de la ciudad en un espacio literario que relativiza su aproximación a los referentes. Podemos añadir que la cronística de Donoso manipula el foco de encuadre, acercándose o alejándose de la ciudad real en consonancia con un arte de enmascaramiento. "Para quien sabe entrar en ella", declara Maurice Blanchot, "una obra literaria es una rica estancia de silencio, una defensa firme y una alta muralla contra esa inmensidad hablante que se dirige a nosotros alejándonos de nosotros" (Cit. en Rancière 14). Jean-Paul Sartre, contemporáneo suyo, reacciona ante esta postura de petrificación, tributaria de "la pasión de Flaubert por los poemas en lenguas muertas" (Rancière 25). Sartre anticipa y defiende así la posibilidad de una poética transitiva ${ }^{9}$, es decir, de una literatura "en la que el verbo es intermediario entre autor y lector" (25). Su contraparte, una poética intransitiva, auspicia "una

9 En varios artículos que Donoso escribe a mediados de los ochenta -"Efemérides" (1984) y "El paisaje borrado" (1987), entre otros- se observan relaciones entre la biografía del autor, la situación política de Chile en aquel momento y la interpelación a los lectores. De acuerdo a Sartre, esta forma de enunciación revela la intermediación de la palabra. En efecto, para el filósofo la transitividad de la expresión se manifiesta en una ética que vincula al escritor con sus creaciones, y que involucra también la participación del lector: "El arte de un autor me obliga a crear lo que me comunica, es decir a comprometerme. De modo que ambos tenemos una responsabilidad con el universo. Debido a que este universo se construye a partir del esfuerzo común de nuestras libertades, y porque el autor, conmigo como medio, ha tratado de integrarlo a la esfera de lo humano, este universo debe comparecer verdaderamente en sí mismo. Y si este universo no es en realidad la ciudad de destino que debería ser, entonces debe convertirse en una etapa del viaje. En resumen, en un llegar a ser, no en una masa sofocante, sino en un punto que nos situará en la ciudad de destino". En What Is Literature?, 1949, pp. 61-62. Traducción mía. 
literatura en la que el medio se vuelve fin, en la que la palabra deja de ser el acto de un sujeto para transformarse en un soliloquio mudo" (25). Desde estos antecedentes, Jacques Rancière aborda la condición de la literatura moderna en La palabra muda, acentuando el estatuto que sostiene el paso de un enfoque transitivo a otro intransitivo. En las crónicas de José Donoso estas miradas cristalizan en un juego de cercanía/lejanía hacia la ciudad y sus prácticas cotidianas. Como se especificará en el siguiente capítulo, nuestra intención no es zanjar el predominio de un enfoque sobre otro, sino más bien determinar el modo en que ellos interactúan en la enunciación de la ciudad de Santiago.

\section{MUDEZ Y "ENCAMAMIENTO" COMO SIGNATURAS DEL SILENCIO}

En las crónicas seleccionadas para este estudio, observamos que las prácticas urbanas degradadas reclaman un lugar en el espacio de la escritura, y por añadidura, en el lenguaje de las creaciones literarias. En "Lecturas de verano" (1986), leemos:

Recuerdo que cuando publiqué mi primera novela, Coronación, [...] se me criticó mucho en mi país por tratar un "tema decadente" como el de la vejez [...]. Veo, sin embargo, que últimamente este tema ha tomado la delantera: creo que son diez los cuentos del último certamen $\mathrm{O}$. Henry que tienen como personaje central a un viejo o una vieja: metáfora de la muerte, de los valores del pasado ahora perdidos, nostalgia por una sociedad con mayor estructura, de la mala conciencia, de la disolución de un mundo (Artículos 341).

De modo similar a lo expuesto en este pasaje, las crónicas surgen de la percepción de un mundo que se desintegra, con énfasis en las relaciones del autor con el pasado de la ciudad. Donoso relaciona esta crisis con fuerzas que imprimen una caducidad sobre las prácticas y subjetividades urbanas, clausurándolas anticipadamente.

Bajo esta perspectiva, la mudez en la cronística de José Donoso bien pudiera leerse como una signatura, es decir, como indicio que no remite simplemente a un signo, sino a la operación que lo hace legible al interior de un régimen discursivo (Agamben 59-60). El concepto de signatura permite apreciar cómo el silencio se manifiesta en los espacios urbanos y, más específicamente, 
cómo esta vacuidad adquiere valor metafórico al interior de la escritura. La aparente neutralidad de este silencio queda en entredicho cuando se examina su función en la poética que interviene en la construcción literaria de Santiago. Esta poética convocará así a un narrador dispuesto a reconocer y articular el idioma de la ciudad: "En Chile, carecemos del orgullo de nuestro idioma vernáculo, y sin ese orgullo, Santiago parece una ciudad sin alma, y sin voz, sin su Susana Rinaldi. No hay un escritor que se haya identificado profundamente con un espacio santiaguino, y haya hecho de ese barrio su idioma, un estilo, una manera de ver y encarar el mundo" (Artículos 159).

¿De qué forma la escritura de Donoso encara el mundo, específicamente aquel que se expresa en una ciudad desprovista de alma y voz? La relación del escritor con las ciudades se vuelve efectiva en un dialogo en el que observador y espacio intercambian sus respectivos saberes. En una crónica de 1979, "Cita en Tavistock Square", Donoso explica esta relación a la luz de la capital española. El escritor advierte

una especie de gran silencio en Madrid [...]. Me parece que esto se debe a que, como profesional, lo primero que acostumbro buscar en las ciudades que visito son las presencias que el arte y la literatura han ido dejando en ellas -más allá de museos y monumentos-, esas amables sombras que como Virgilio aparecen en esquinas reconocidas al instante pese a nunca haberlas visto, para guiar mi descenso al apasionante infierno que es toda ciudad nueva (Artículos 100).

El autor volverá a invocar estas "amables sombras" en 1981, cuando propone fusionarse sensualmente con la ciudad para que ésta suscite imágenes y narraciones opuestas a la homogeneidad que se impone sobre sus espacios. ¿Qué ignora este silencio madrileño, pese a las innumerables escenas callejeras y públicas que inspiraron a generaciones de escritores? "El detalle de lo cotidiano", responde Donoso, "lo espontáneo, la leyenda calurosamente conservada unida a un sitio, la placa recordatoria, el 'Aquí vivió..."” (101).

En sus "Tesis de filosofía de la historia", Walter Benjamin esgrime que la interpretación del pasado no pretende articular sucesos a imagen y semejanza de su existencia pretérita, como aconsejan los métodos historicistas tradicionales. Implica, más bien, la apropiación de un recuerdo en el instante de un peligro; en el momento en que nuestra conciencia nos revela el servicio que hemos ministrado a una fuerza dominante (180). Ahora bien, en las crónicas de Donoso, el pasado emerge a través de una práctica en la que el "cronista narra los acontecimientos sin distinguir entre los grandes 
y los pequeños, dando cuenta de una verdad: que nada de lo que una vez haya acontecido ha de darse por perdido para la historia" (Benjamin 178179). En 1981, Donoso retorna a Chile y escribe varios artículos en los que reflexiona más detenidamente sobre sus relaciones con la ciudad y la cultura nacional: "En nuestro mundo hispanoamericano se tiene poco respeto por las huellas del pasado [...]. Pocas familias conservan acerbos de papeles y fotos, ni archivos. Sólo se conservan las cosas que tiene valor de mercado". Similar a las reflexiones benjaminianas sobre los espacios arruinados por el progreso de la modernidad, el autor concluye que "ningún detalle del pasado es negligible [sic]" (Artículos 483).

Establecimos que una vía de acceso a esta mudez es mediante su equivalencia a una signatura, vale decir, a través de una marca que la hace visible. Escindida de un ámbito semiológico, la mudez quedaría provista de una función, a saber señalizar la emergencia del silencio y el espacio discursivo de que es parte. "La teoría de las signaturas", aclara Agamben, "interviene, entonces, para rectificar la idea abstracta y falaz de que existen signos por así decirlo puros y no signados" (89). La mudez, siguiendo este argumento, instala la presencia del silencio y lo sitúa en una historia que deja de representarlo, meramente, como el resultado de una muerte natural. El silencio de Santiago emerge y es percibido a través de la mudez, en tanto un fenómeno "nunca está dado de modo neutral, sino que siempre está acompañado por un índice o por una signatura, que lo constituye como imagen y condiciona temporalmente su legibilidad" (101). En principio será la percepción de una ciudad muda la que estimule una poética urbana que intentará sustituir la fuga de la voz por un idioma.

A partir de recuerdos en las calles Ejército y Dieciocho, Donoso describe el "barrio bajo" en "De mis tías, la más bella" (1982) como una "vastísima sección, ni popular ni burguesa, y con la que la clase media económica quiere tener lo menos que ver posible, [que] se ha mantenido como las ruinas de una ciudad extraña enclavada dentro de este Santiago que quiere ser moderno" (Diarios 298). Se introduce luego una imagen que permite interpretar el silencio santiaguino:

al caminar por estas calles tan unidas a mi infancia pienso que en el fondo, es un barrio que se ha "encamado", para esperar la muerte, pero que es sin duda la escenografía, conservada como con la perfección de Pompeya, bajo el polvo del tiempo, de un modo de vida, más modesto y menos pretencioso pero a la vez muy nuestro, que se ha desvanecido (298). 
Este "encamamiento" encuentra su equivalente en la voz inaudible de Santiago, por cuanto ambas condiciones remiten a una inercia que desencadena el deseo de restitución, ya sea a través de la fantasmagoría del recuerdo o por medio de la articulación de una poética. Clarissa, la más bella de las tías, escuchaba melodías en una "cajita de música", cuyas melodías "no son las mismas que se oyen desde las ventanas de las casas erizadas de antenas de televisión de Agustinas y Avenida Portales, de Cienfuegos y de Santo Domingo cuando uno se da el trabajo de ir, como en un peregrinaje a otra ciudad que encierra el pasado, al Barrio Bajo" (299). Aun en este brevísimo pasaje logramos constatar una narración en la que se entrecruzan la inmediatez de las contingencias con una disposición metafórica del espectáculo urbano ${ }^{10}$. Un objeto aparentemente inocuo como una caja de música deviene, al mismo tiempo, imagen literaria y artefacto que suscita una crítica a las modernizaciones espurias que se esparcen sobre la ciudad.

En definitiva, José Donoso habla de una experiencia cotidiana que se ha encamado -fugada en el tiempo, como las melodías antiguas-y del surgimiento de un horizonte globalizado. En "Los barrios bajos de Santiago" (1982), leemos: "en ninguna de esas mansiones de tabiquería y mármol simulado, ahora subdivididas, en esas callejuelas torcidas alrededor del antiguo Teatro Carrera $[. .$.$] falta la televisión: de modo que esa gente debe ser exactamente$ igual, y sus ideas y conversaciones muy parecidas a la arrogante gente que habita los beaux quartiers del Barrio Alto" (Diarios 304). Estas líneas revelan un imaginario de la vida cotidiana en sectores que, pese a sus diferencias sociales, comparten un estrecho vínculo con las mercancías publicitadas en televisión ${ }^{11}$. En este contexto, la vida política también prefigura la desaparición del civismo en los espacios públicos. En "País 'desinflado"” (1987), Donoso

10 Sobre este aspecto sigo los planteamientos de Paul Ricoeur, para quien la "metáfora es una creación instantánea [y no simplemente la sustitución de una palabra por otra], una innovación semántica que no tiene reconocimiento en el lenguaje ya establecido, y que sólo existe debido a la atribución de un predicado inusual o inesperado. [...]. En síntesis, una metáfora nos dice algo nuevo sobre la realidad". Esta novedad se complementa con el carácter creativo que detenta la imagen en el contexto de este estudio. En Teoría de la interpretación, 1995, pp. 65-66.

11 Estudios de Néstor García Canclini explican cómo los sujetos interpretan simbólicamente el gigantismo de las ciudades latinoamericanas. Ver "Diálogo sobre imaginarios urbanos", en Imaginarios urbanos, 2010. Otro trabajo del autor que aborda estas problemáticas con énfasis en la expresión heterogénea de la modernidad es Culturas hibridas. Estrategias para entrar y salir de la modernidad, 1990. 
percibe "una especie de baja presión general en la vida diaria y política, de borroneo, como si una goma gigante se ocupara de borrar de la memoria de la ciudadanía cada acontecimiento que resulta incómodo recordar" (Diarios 329-330).

La percepción de la ciudad en las crónicas destaca condiciones urbanas que remiten a ausencias que socaban los juegos creativos del espacio. La mudez, el encamamiento y las memorias borradas indicarían la trayectoria de una voz imbunchada, una palabra traicionada por fuerzas en constante transformación que tergiversan la posición del sujeto y la fisonomía de la ciudad. Con precedentes en artículos publicados en los sesenta ${ }^{12}$, el silenciamiento de estos hitos confirma la relación entre la mudez de los espacios y la dificultad con la que el autor reanuda su contacto con la ciudad en 1981. Ambas discapacidades sugieren el letargo de los encamados: después de la música, irá desapareciendo la imagen de Santiago que el autor ha construido en su memoria. Al respecto, y usando un concepto sobre el cual Donoso vuelve repetidas veces, la poética que enuncia la ciudad en clave literaria en las crónicas surge de la perplejidad ante la "disolución de un mundo". Esta desintegración se manifiesta, entre otras cosas, en el término de un recorrido venturoso por Santiago y en la consolidación de un modo uniforme de habitar los espacios públicos ${ }^{13}$.

12 Ver "En el infierno de la locura" (1962), "Lo divino y profano en Yumbel" (1963), "Las animitas: un culto de pueblo" (1963) e "Isla británica en Chile" (1964), reunidos en El escribidor intruso. Además de acentuar subjetividades derruidas por la modernización, estos trabajos se alinean con la producción narrativa de Donoso. El cuidado con el que la Manuela remienda su vestido de española en El lugar sin límites (1965) o los envoltorios que las viejas acumulan en El obsceno pájaro de la noche (1970) son gestos que articulan, con notable sentido estético y simbólico, una "forma de encarar el mundo".

13 Según Simmel, lo que "caracteriza el concepto de aventura y le distingue de todos los fragmentos de la vida, que como meros frutos de lances de la fortuna se sitúan en su periferia, es el hecho de que algo aislado y accidental pueda responder a una necesidad y abrigar un sentido". Sobre la aventura, 2002, p. 22. En "El retorno del nativo" (1981) y "Jugando al diccionario" (1995), Donoso sugiere que este sentido es arrebatado por estrategias que imponen una forma predecible de interactuar con la ciudad. 


\section{LA VOZ: MATERIAL FUNDANTE DE LA POÉTICA URBANA}

En la literatura donosiana, el motivo de la voz establece zonas críticas sobresalientes animadas por sujetos extraviados en su propia habla o en búsqueda de un lenguaje. Los narradores y protagonistas de El obsceno pájaro de la noche (1970), El jardín de al lado (1981) y La desesperanza (1986) encarnan formas en que el desgarro de la palabra, en estados de delirio o "seca" artística, legitima la presencia de estas subjetividades en el mundo. Las crónicas, por su parte, enuncian una ciudad muda desprovista de un idioma vernáculo. Las siguientes reflexiones detallan el lugar que Donoso otorga a la voz en su escritura:

La dicotomía realidad-ficción no puede separarse la una de la otra. Conservan una misteriosa distancia entre ellas que también es unión; es un lugar donde está implantada la "voz" del novelista. De esa "voz" esencial se desprenderá el fenómeno que se está contando; son sólo pilas de ladrillos en bruto, cerros de cemento para la obra aún sin forma, antes que la voz característica se haya articulado, transformado en lenguaje ${ }^{14}$ (Diarios 130).

Si bien la cita examina la voz al interior de la obra narrativa de Donoso, el comentario proporciona valiosos datos para el estudio de las crónicas. Éstas revelan la voz de la ciudad en grados de "novelación" que se manifiestan, por un lado, en la elaboración de una tesitura poética y, por otro, en el convencimiento de que la materialidad de los espacios estimula fantasías y narraciones (Artículos 205). La imposibilidad de separar lo real de aquello que ha sido creado literariamente confirma, además, un diálogo productivo entre experiencia y escritura.

El juego de distancia y unión, al interior de un ensayo sobre la creación literaria, nos remite a la crítica de las técnicas modernas de reproducción en los trabajos de Walter Benjamin, con lo que se abre la posibilidad de

14 El texto corresponde al manuscrito "Cultura, memoria, realidad", base de una conferencia de 1994, según las anotaciones de Patricia Rubio en José Donoso. Diarios, ensayos, crónicas. En conversación con Carlos Cerda, Donoso vuelve a enfatizar las relaciones entre ficción y realidad: "Creo que la gente no lee con imaginación literaria; la gente se estanca en una pequeña pocita y dice 'esto de aquí para acá es memoria, esto de aquí para acá es imaginación, literatura'. La prueba más grande es la cantidad de veces que he tenido que oír ‘ $¡$ ah, pero esto no se parece en nada a la verdad!’”. En Donoso sin límites, 1997, p. 164. 
interpretar el vínculo realidad-ficción bajo la lucidez del concepto de aura. La solidaridad entre realidad y ficción acusa elocuentemente una presencia biográfica que, previa transformación, se hace audible en una voz. La elocuencia de esta imagen acústica, o su autenticidad, se contrapone a las lógicas que ordenan la circulación y la percepción de los objetos en los espacios urbanos modernizados. La presencia de la voz y sus variantes, tales como el idioma, la música y la literatura urbanas, establecen un contrapunto notable. En efecto, al "alejarse" del imperio de la imagen visual, la articulación de una poética tensiona estética y metafóricamente el recurso de la voz -la voz en los barrios de Recoleta e Independencia; "la voz del novelista"-, promoviendo una alteridad perceptual que transgrede la representación especular de las prácticas urbanas ${ }^{15}$. Asumiendo que esta poética sostiene, en consecuencia, la "presentación" de una voz y "la manifestación irrepetible de su lejanía" (Benjamin 24), la ciudad en las crónicas surge y se problematiza a partir de una relación acústica con los espacios silenciados.

Esta relación también es discernible en ensayos y fragmentos de diario del autor. En "Cultura, memoria, realidad" (1994), Donoso enfatiza que "la 'ceguera' de los novelistas debe tener tal potencia que se pueda cambiar el mundo obliterado por la ceguera, por este otro mundo, el de la 'voz' autoral, el de la fantasía, la ficción, el mundo inventado" (Diarios 131). Privilegiando una teoría impersonal ${ }^{16}$, el autor concluye que "si no fuera así escribir sería sólo una manera de celebrar el yo, no el trabajo de elaborarlo para llegar a un fin necesario pero desconocido" (131). Como sugiere la cita, "El retorno

15 De acuerdo con Henri Lefebvre, la representación es "el doble y el olvido de la presencia, el sustituto que suple la desaparición, cobrando formas diversas (reflexión, imagen, signo, etc.). La representación, sustituto de la presencia en la ausencia, la desplaza y la reemplaza, desdoblamiento y redoblamiento (por lo tanto propenso a una alienación, lo repetitivo)". En La presencia y la ausencia, 2006, p. 300.

16 Es probable que Donoso haya concordado con las ideas centrales de T. S. Eliot en el ensayo "La tradición y el talento individual" ["Tradition and Individual Talent", 1919]. "El punto de vista que contradigo", acentúa Eliot, "se relaciona con la teoría metafísica de la unidad sustancial del espíritu. Quiero decir que el poeta no posee una 'personalidad' para expresar, sino un medio que es sólo eso: un medio, no una personalidad, a través del cual las impresiones y las experiencias se combinan en formas peculiares e inesperadas". En The Heath Anthology of American Literature, 1990, p. 1310. Traducción mía. Queda aún por resolver el lugar que ocupa la visión literaria de T. S. Eliot en la obra de José Donoso y, más específicamente, su relevancia en el diseño de una poética que busca traducir la experiencia sensible en una forma artística inédita. 
del nativo", "El espacio literario" y "Voz e inventario" reflejan con distintos matices un abandono deliberado de los referentes urbanos y su transformación sinestésica. Santiago se "observa" a través de un oído deseoso de escuchar sus ecos literarios, atento a descubrir el idioma vernáculo de la ciudad en un recorrido in situ por los barrios tradicionales.

$\mathrm{Al}$ establecer ciertas afinidades entre la película El juego de las lágrimas (1992) y El lugar sin límites en uno de sus diarios personales, Donoso imagina un guión sobre

la mudez de la hija de alguien (el padre la promete en matrimonio a un amigo antes de que aprenda a hablar y no aprende nunca y queda muda para toda la vida. Ver a quién le sucede esto en el siglo XIV). La maldición divina por jugar con la identidad y la integridad de otro ser. El poder de Dios para ver y juzgar lo que nosotros no vemos ni juzgamos. Un personaje es un poeta, el que le enseña a la niña a reconocer los sonidos en las palabras escritas. La niña. El padre que es pura codicia, y la salvación por la letra escrita, por la imagen (Cit. en Pilar Donoso 354).

En 1994, el autor crea, de forma inadvertida, una trama que refleja fielmente el enmudecimiento de Santiago una década antes. Al convenir una simetría entre la niña muda y la ciudad en esta lectura, el escritor/poeta que enseña los sonidos deviene artífice de una realidad que se legitima "por la letra escrita, por la imagen". Conviene destacar que esta imagen no se restringe a un orden visual; remite, más bien, a la impresión de esas "amables sombras" (Donoso, Artículos 100) que el discurso literario convoca en la retina de la imaginación. Se impone así nuevamente un modo de habilitación literaria por sobre la homogeneización especular del paisaje urbano.

Confirmamos una tendencia en las crónicas, presente en variedad de tonos y con mayor claridad en los artículos de fines de los ochenta. Nos referimos a la intención de restituir el habla usurpada a una ciudad que, de acuerdo con el autor, posee méritos suficientes para articular un idioma propio. "La literatura es el olvido y la recuperación de la imagen a través de la palabra desde más allá del olvido", reconoce Donoso. "El olvido es lo que practicó toda mi generación de novelistas en el exilio, efectuando la recuperación, la reconstrucción mediante el lenguaje" (Cit. en Pilar Donoso 363). Se configura asimismo una relación más explícita entre una escritura y una poética que convergen en la recuperación de las memorias que vinculan al autor con su país. Sobre este punto, y recordando a los escritores de su 
generación, Donoso señala: “no podíamos escribir sobre los mundos extraños donde éramos marginales, teníamos que vivir en alguna parte y vivimos en la reconstrucción de mundos ahora inaccesibles. La memoria es la palabra. Era cuestión de reconstruir con la palabra" (Cit. en Pilar Donoso 363-364). En la cronística del autor temas fundamentales como la pérdida irrevocable de un mundo degradado por el olvido, o la absolutización del presente, tienden a permanecer irresueltos y, por lo tanto, sujetos a una constante revisión. Siguen una trayectoria con el retorno del nativo a Santiago a principios de los ochenta, y se desplazan a lo largo de la década formulando una crítica a una época desprovista de energías creativas.

En "Desde allá", el autor recuerda su regreso definitivo Chile y la decisión de fijar domicilio en Santiago:

No volví para sumergirme en la "pesadumbre de los barrios que han cambiado" que canta Rinaldi en el tango "Sur". Sin embargo me encontré aquí con la repetición idéntica, aunque en otra clave, de las miserias de que huí: es lo que en este momento me hace tan difícil como antes escribir este extraño y cruel presente, ya que esas mismas miserias parecen haber resucitado con otros rostros, y acosan igual que antes (Diarios 314).

Las carencias de un ambiente urbano-cultural enclaustrado se reiteran en la historia nacional, demostrando la vigencia de un poder que adopta formas distintas sin abandonar sus bases. Si en "Efemérides" (1984) este poder se relaciona con "el peso de la noche" ${ }^{17}$, en "El retorno del nativo" los continuadores de esta fatalidad nocturna serán los miembros de una "oligarquía contemporánea" encargada de situar las "huellas de nuestro modesto pasado [...] dentro de un contexto político-económico-social” (Artículos 206-207). Las miserias que Donoso advierte en Santiago se acentúan a medida que la modernización de los espacios borronea la imagen pretérita de la ciudad que aún pervive en el recuerdo del autor. La estética de una arquitectura

17 Joaquín Edwards Bello aborda este mito en crónicas que discuten su naturalización por parte de frondas aristocráticas en constante reverdecimiento. Destacan "En el tren presidencial" de 1925, "Pobres y ricos" y "Habló el roto chileno", de 1962, en Crónicas. Por su parte, los trabajos de Donoso instalan una crítica del poder que utilizará esta imagen como un dispositivo que revela el abandono de la ciudad a una inercia que empobrece las prácticas cívicas y la creación artística. Desde un trasfondo histórico, el peso de la noche deja así en evidencia tanto su ubicuidad como su impacto en la vida cotidiana. 
modesta pero propia, la identidad de los "barrios bajos" y los hitos del pasado languidecen en una "época de restauraciones". En Chile, sentencia Donoso, "nos quedamos en el inventario, y en vez de redescubrir, como en Buenos Aires se ha 'redescubierto' (para bien o para mal) San Telmo, aquí 'restauramos"' (Artículos 160).

Finalmente -y considerando las reflexiones que el autor vierte en el conjunto de sus escritos referenciales- las crónicas modelan espacios contrapuestos a la uniformidad mediante una poética que aborda la ciudad desde la labor del novelista. El autor es consciente de la recomposición de la realidad que se amalgama en sus creaciones, sustancial para determinar una poética en sus crónicas. En la introducción a "La palabra traicionada" (1988), y citando al crítico norteamericano Northrop Frye, José Donoso concede que "los escritores $\mathrm{y}$ artistas trabajan con lenguaje figurado, en tanto que los intelectuales trabajan con conceptos" (Diarios 337). Establecidos los límites que separan una lógica de otra, Donoso confirma que

a poco andar yo una página se me llena irrefrenablemente de objetos lingüísticos que no conducen a aclarar la idea abordada, sino que la acarician, la rodean, como en una danza, la excitan, la adornan, la magnifican, aportando otra claridad, un conocimiento distinto al que aportan los conceptos y la información, adquirido y repartido mediante algo parecido a sistemas nerviosos alternativos que producen una lucidez distinta (337).

En la producción cronística del autor, el surgimiento de esta lucidez es consecuencia de una poética que reformula la conspicua presencia visual de los espacios y prácticas urbanas. Apreciamos así una forma de enunciación otra que, sostenida en la imagen de la voz, amplifica el dominio especular prevalente en la construcción discursiva de las ciudades. Por otro lado, las crónicas instancian una escritura que se aproxima a los referentes urbanos en diversos grados de cercanía/lejanía. Con ello el registro acústico y visual de Santiago obedece, en principio y en último término, a las prerrogativas que el artificio de la palabra literaria concede al escritor. 


\section{CONCLUSIONES}

La búsqueda de una forma literaria para la representación de la ciudad en la cronística de José Donoso surge de una circunstancia biográfica: la necesidad acuciante del sujeto de expresarse despolitizadamente desde un espacio arraigado en el arte de la escritura. Esta intención se agudiza desde inicios de los ochenta con la publicación de "El retorno del nativo", "Voz e inventario" y "El espacio literario" y, cabe destacar, con la creación de personajes-artistas que transitan por dilemas similares en El jardin de al lado o La desesperanza. La poética urbana que emerge en la escritura de Donoso se inscribe, en otras palabras, en un trabajo de deformación cuya trayectoria no surge de improviso. Presente desde temprano en su narrativa -incluso en enfoques realistas con los que se abordan los grupos sociales o el mismo espacio citadino en Coronación-, el artificio que implica esta deformación no hace otra cosa que intersectarse, y problematizarse, con la producción cronística del autor en los ochenta.

En esta década, las crónicas de Donoso, y la poética que las moviliza, se contraponen al silencio homogeneizador que enmudece la ciudad de Santiago. En consecuencia, el trabajo cronístico del autor logra resemantizar la imagen de esta ciudad silente por medio del desplazamiento que aportan las figuras de la metáfora y la metonimia. La ausencia de una voz actúa así, en ambos casos, como un índice que remite a la condición museificada de la cultura y la sociedad chilena, según leemos en "Cultura, memoria, realidad", "Efemérides" y "El retorno del nativo". En esta última, el autor critica abiertamente el modo de llevar a cabo praxis cívicas y ciudadanas en los espacios públicos: "antes imperaba el 'servicio', que es lo que marca a una clase dirigente que era la única clase entonces capacitada; siento que ahora impera el sentido de lucro y la oligarquía contemporánea que lleva las riendas de mi país y determina el rostro de mi ciudad [...] parece haber perdido un poco este sentido de "servicio"" (Artículos 209). Cabrá establecer en estudios posteriores si, a partir de un desplazamiento metonímico, la ciudad enmudecida pudiese interpretarse también como una metáfora de la ausencia de una literatura urbana y de un "escritor de ciudad" (Escribidor 220).

Los espacios que José Donoso aborda en sus crónicas, desde las prácticas cotidianas hasta los paisajes urbanos y literarios en la ciudad, se caracterizan por desplegar una poeticidad compleja en cuanto a su recepción estética. Son ámbitos evocados desde ángulos diversos que no se restringen, como ya discutiéramos, a los dominios especulares o a una retórica tradicional. En 
este sentido, los espacios que Donoso construye en sus escritos referenciales acusan demarcaciones porosas que se informan unas a otras procurando la habilitación de una voz en la ciudad. Las relaciones de tipo sinestésico, por ejemplo, generan la confluencia simultánea de la vista y la audición en los recorridos por los barrios pericentrales en "Voz e inventario" y "De mis tías, la más bella". No obstante, y de modo quizás más relevante, el entrecruce de estos dominios instala un tejido retórico, un vocabulario que posibilita la narración de Santiago desde un tropo que se reitera en variedad de tonos y énfasis. Nos referimos a la percepción de una inopia manifiesta en la precariedad de un idioma urbano que no "vibra aún con las resonancias de nuestra música y de nuestra poesía que conmuevan sus piedras" (Artículos 162).

Ahora bien, las crónicas seleccionadas para este estudio revelan que la articulación de una poética compromete, además, la intervención de la voz del enunciante. Esta voz prefigura en la escritura no meramente como una función textual, sino sobre todo como un valor biográfico que mediatiza los vínculos entre la referencialidad y su transformación en el discurso cronístico. La visión de mundo que aporta esta biografía supone la constitución de un sujeto para quien es "probable que el precio del exilio y del retorno sea nunca dejar de ser un extranjero en su propio país y en su propio idioma" (Artículos 218). En los artículos "La palabra traicionada" y "La libertad y el lirismo", José Donoso antepone una sordera deliberada al clamor que le exige constituir su identidad desde una coyuntura socio-política. En uno de sus cuadernos personales, el autor extraña "la variedad de máscaras que uno podía conjugar [en el extranjero], y uno se da cuenta de que la identidad es más rica si es una suma de máscaras diversas, no una sola 'persona' esclavizadora" (Pilar Donoso 253). Subyace en estos escritos un entendimiento descentrado del sujeto, postura ontológica que también se manifiesta en la emergencia de las prácticas y subjetividades urbanas en las crónicas.

Podemos relacionar este enmascaramiento con la deformación que implica una poética, según hemos visto en otros artículos y fragmentos de diario. Enmascarar significa también introducir un artificio en la lectura de la realidad, disfrazarla ligeramente a fin de desdibujar sus contornos y presentarla distinta, pero conservando aún sus rasgos constitutivos. Este artificio conlleva un movimiento continuo de distanciamiento y cercanía en relación con un objeto - pienso en la ciudad, las prácticas urbanas, el sujeto de la enunciación-y sobre el cual recaen las prerrogativas del artista. $\mathrm{O}$ como diría Donoso al observar los retratos de los fotógrafos del siglo XIX, un juego que ajusta y desajusta el foco de la cámara. En el plano de su relación con 
la escritura, ésta encierra una "misteriosa correspondencia realidad-ficción que no pueden separarse la una de la otra sin empobrecerse" (Diarios 132).

Como se plantea en "La palabra traicionada", la enunciación compromete una versión otra de la ciudad a través de una "lucidez distinta". El presente estudio ha identificado esta lucidez con una poética que al desnaturalizar los referentes deja en evidencia la mudez de la ciudad de Santiago. Identificable en una primera instancia, Santiago se reformula poética y estéticamente -a través de una percepción que suscita fantasías y narraciones inéditas- y aparece como una obra que impugna el letargo de su referente inmediato. Es por medio de una poética sustentada en la imagen de la voz que las prácticas y subjetividades normalizadas encuentran un espacio de articulación literaria al interior de la cronística de José Donoso. Finalmente, y apelando a un término que el autor reserva para las creaciones que estimulan un mito y un idioma en "Voz e inventario", la enunciación de Santiago en las crónicas produce una literatura referencial de "alto rango". Según constatamos en la lectura de los trabajos seleccionados para este estudio, dicho rango obedece a una imagen de la ciudad que surge desde dominios literarios y críticos contrarios al orden monocromático que imponen los inventarios y las restauraciones.

\section{BIBLIOGRAFÍA}

Agamben, Giorgio. Signatura rerum. Trad. Flavia Costa y Mercedes Ruvituso. Buenos Aires: Adriana Hidalgo Editora, 2009.

Benjamin, Walter. "Tesis de filosofía de la historia". Discursos interrumpidos I. Filosofía del arte y de la historia. Trad. Jesús Aguirre. Madrid: Taurus, 1989. 175-192. I.15-57.

"La obra de arte en la época de su reproductibilidad técnica". Discursos interrumpidos

Cerda, Carlos. Donoso sin límites. Santiago: LOM, 1997. 149-178.

De Certeau, Michel. La invención de lo cotidiano I: Artes de hacer. Trad. Alejandro Pescador. México, D. F.: Universidad Iberoamericana, 2007.

Deleuze, Gilles. “Control y devenir”. Conversaciones: 1970-1990. Trad. José Luis Pardo. Santiago: Edición electrónica <www.philosophia.cl/Escuela $>$ Escuela de Filosofía Universidad ARCIS, 1990. 143-154.

Donoso, José. Artículos de incierta necesidad. Ed. Cecilia García Huidobro McA. Santiago: Alfaguara, 1998.

El escribidor intruso. Artículos, crónicas y entrevistas. Ed. Cecilia García Huidobro McA. Santiago: Ediciones Universidad Diego Portales, 2004. 
José Donoso. Diarios, ensayos, crónicas. Ed. Patricia Rubio. Santiago: RIL Editores,

2009.

Donoso, Pilar. Correr el tupido velo. Santiago: Alfaguara, 2009.

Edwards Bello, Joaquín. Crónicas. Santiago: Zig-Zag, 1964.

Eliot, T. S. "Tradition and Individual Talent". The Heath Anthology of American Literature. Nueva York: Houghton Mifflin, 1990.

García Canclini, Néstor. Culturas hibridas. Estrategias para entrar y salir de la modernidad. México D. F.: Grijalbo, 1990. Imaginarios urbanos. Buenos Aires: Eudeba, 2010.

Godoy, Eduardo. “Diálogo con José Donoso”. Revista Signos 2 (1971): 23-32.

Lefebvre, Henri. La presencia y la ausencia. Contribución a la teoría de las representaciones. 1980. Trad. Oscar Barahona y Uxoa Doyhamboure. México D.F.: Fondo de Cultura Económica, 2006.

Mongin, Olivier. La condición urbana. La ciudad a la hora de la mundialización. Trad. Alcira Bixio. Buenos Aires: Piadós, 2006.

Morales, Leonidas. "Introducción a la obra de José Donoso". José Donoso, 70 años. Coloquio internacional de escritores y académicos. Santiago: Ministerio de Educación, 1997. 38-45. La escritura de al lado. Géneros referenciales. Santiago: Editorial Cuarto Propio, 2001. "Pedro Lemebel: género y sociedad". Aisthesis 46 (2009): 222-235. Novela chilena. José Donoso y Diamela Eltit. Santiago: Cuarto Propio, 2004.

Promis, José. "Programas narrativos de la novela chilena en el siglo XX". Revista Iberoamericana 168-169 (1994): 925-933. 15-42.

Rama, Ángel. "La modernización literaria latinoamericana". La crítica de la cultura en América Latina. Caracas: Biblioteca Ayacucho, 1985. 82-96.

Rancière, Jacques. La palabra muda. Ensayo sobre las contradicciones de la literatura. 1998. Trad. Cecilia González. Buenos Aires: Eterna Cadencia, 2009.

Ricoeur, Paul. Teoría de la interpretación. Discurso y excedente de sentido. Trad. Graciela Monges Nicolau. México, D.F.: Siglo XXI Editores, 1995.

Rotker, Susana. La invención de la crónica. Buenos Aires: Letra Buena, 1992.

Sartre, Jean Paul. "Why Write?”. What Is Literature? New York: Philosophical Library, 1949. 38-65.

Simmel, Georg. Sobre la aventura. Trad. Gustau Muñoz y Salvador Mas. Barcelona: Península, 2002. 